\title{
Cytokines in Human Colostrum and Neonatal Jaundice
}

\author{
VINCENZO ZANARDO, ROSANNA GOLIN, MAURIZIO AMATO, DANIELE TREVISANUTO, FLAVIANO FAVARO, \\ DIEGO FAGGIAN, AND MARIO PLEBANI
}

\begin{abstract}
Department of Pediatrics [R.G., D.T.], Padua University, 35128 Padua, Italy; Institute of Laboratory Medicine [F.F., D.F., M.P.], Padua University, 35129 Padua, Italy; University of Berne School of Medicine [M.A.], 104-Berne, Switzerland
\end{abstract}

\begin{abstract}
Breast-fed infants have higher bilirubin levels than formula-fed infants, possibly because of variations in the composition of the breast milk. The aim of this study was to investigate whether there is a relationship between cytokine levels in the colostrum of nursing mothers and neonatal jaundice (NJ). Breast milk samples were collected from breast-feeding mothers of healthy fullterm neonates, 32 with $\mathrm{NJ}$ and 29 without jaundice. The concentrations of IL-1 $\beta$, IL- 6 , IL-8, IL-10, and tumor necrosis factor (TNF)- $\alpha$ were measured by chemiluminescence enzyme immunometric assays. Mothers of infants with NJ had a higher concentration of IL- $1 \beta$ in colostrum, compared with those feeding neonates without $\mathrm{NJ}$, and similar trends were seen for IL-6, IL-8, IL-10, and for TNF- $\alpha$. The concentrations of IL- $1 \beta$ significantly correlated with IL-6, IL-8, IL-10, and TNF- $\alpha$ concentrations, but not with serum bilirubin levels of infants with NJ. In conclusion, the concentrations of IL- $1 \beta$ were increased in colostrum from breast-feeding mothers whose infants had NJ. The correlation between the concentrations of cytokines involved in the function of hepatic uptake and excretory systems and in the enterohepatic circulation of bilirubin provides additional data to the delineation of the cascade of pathophysiological events that can lead to NJ. (Pediatr Res 62: 191-194, 2007)
\end{abstract}

$\mathrm{B}^{\mathrm{r}}$ reast-fed infants have higher bilirubin levels than formula-fed infants (1). The jaundice of breast-fed infants is commonly of undetermined etiology (2-4). Suggested mechanisms for these findings include insufficient milk transfer to the neonate (5), inhibition of hepatic excretion of bilirubin (6), and increased intestinal absorption of bilirubin $(7,8)$.

Inhibition of hepatic excretion of bilirubin could explain the jaundice associated with human milk consumption, and early studies suggested that exposure to acquired cholestatic injury such as drugs, hormones, proinflammatory cytokines, or biliary obstruction or destruction results in an altered expression and function of hepatic uptake and excretory systems, changes that may maintain and contribute to cholestasis and jaundice (9). In particular, increased production of IL-8 and IL-10 has been reported in patients with biliary obstruction and jaundice $(10,11)$. Moreover, the cholestatic effect of cytokines (e.g. IL-1 $\beta$, IL-6) is believed to result from the repression of genes that normally mediated the hepatic uptake, metabolism, and biliary excretion of bile salts and various nonbile salt organic anions such as bilirubin $(12,13)$. In addition, IL-1 $\alpha$, IL-6,

Received October 5, 2006; accepted March 7, 2007.

Correspondence: Vincenzo Zanardo, M.D., Department of Pediatrics, Padua University School of Medicine, Via Giustiniani, 3, 35128 Padua, Italy; e-mail: zanardo@pediatria. unipd.it and tumor necrosis factor (TNF)- $\alpha$ were found to decrease the glucuronidation activities dose dependently (14).

Intestinal absorption is a key step in the enterohepatic circulation of bilirubin because bilirubin is more easily absorbed from the intestine than are bilirubin glucuronides. Increased intestinal absorption of bilirubin (15), facilitated by breast milk rich in $\beta$-glucuronidase (16) or via some other mechanisms such as delayed passage of meconium, the establishment of a population of intestinal bacteria that converts bilirubin glucuronides to various urobilinoids and therefore reduces the availability of bilirubin for intestinal absorption (7), and casein hydrolysates that inhibit $\beta$-glucuronidase in the intestine (17) currently appear to be another likely mechanism that explains neonatal jaundice associated with breast-feeding (18). Several studies have shown that enterocytes can constitutively express pro-inflammatory cytokines $(19$, and this response is up-regulated by inflammatory stimuli such as endotoxin and IL-1 $\beta(7,8,17,20)$.

Although cytokines are known to play a critical role both in the function of hepatic uptake and excretory systems and in the enterohepatic circulation, little is known concerning their concentrations and associations within breast milk of mothers feeding neonates with neonatal jaundice (NJ), and, to the best of our knowledge, the effect of colostral milk cytokines on neonatal hyperbilirubinemia has not been previously studied.

The objective of the present study was to investigate whether there is a relationship between cytokines levels in the early milk of nursing mothers and $\mathrm{NJ}$, with the consequent implications on the development of neonatal hyperbilirubinemia.

\section{MATERIALS AND METHODS}

Subjects. Breast milk samples were obtained from mothers hospitalized in the suburban primary maternity care at Noventa Vicentina Hospital, Noventa Vicentina, Italy, from June to December 2004. Collection date and time were recorded, as were infants' birth date, gestational age, birth weight, sex, and NJ (total serum bilirubin levels $>12 \mathrm{mg} / \mathrm{dL}$ ) (20) and mothers' demographic and anthropometrical characteristics (age, parity, BMI), and route of delivery (cesarean section versus vaginal).

Before the infant's birth, at-term pregnant women were asked by experienced and trained research midwives to participate in a prospective study. The women received verbal and written information about the aim and structure of the study. Only healthy women aged 18 y or more, not taking antiinflammatory medications at the time of enrollment, with otherwise uncomplicated gestation, delivery and puerperium and who planned to obtain care for their newborns through rooming-in and exclusively breast-feeding their newborns were eligible. After having accepted participation, the neonatal jaundice history was recorded for each mother. Of the eligible participants, 32 identified as mothers of neonates with NJ requiring phototherapy (21) were recruited for study participation. Control participants included 32 consecutive 
women whose infants did not have a history of neonatal jaundice and matched a neonatal jaundice participant on the basis of overall inclusion criteria. One was excluded from the final analysis because of maternal fever and two for breast-feeding discontinuation.

This study was approved by the Human Ethics Committee of the Department of Pediatrics of Padua University and of Noventa Vicentina hospital.

Milk specimen collection and processing. Breast milk samples were collected during the third $( \pm 12 \mathrm{~h})$ postpartum day. Collection was standardized to reduce bias and potential diurnal variability in cytokine measurements. While blood samples for serum bilirubin studies were routinely done at $0700 \mathrm{~h}$ and $1600 \mathrm{~h}$, milk specimens were obtained in two groups within $1 \mathrm{~h}$ of the first feeding in the morning and in the afternoon, defined between 0800 and $0900 \mathrm{~h}$ and 1700 and $1800 \mathrm{~h}$, respectively. All mothers were able to provide milk at each sampling point. An aliquot of $3 \mathrm{~mL}$ was taken using a manual breast pump (Avent, Suffolk, UK). Samples were temporally stored at $-70^{\circ} \mathrm{C}$ in sterile plastic tubes and used for assays.

Samples were thawed and centrifuged for $10 \mathrm{~min}$ at $1800 \mathrm{rpm}$ at $4^{\circ} \mathrm{C}$, after which the lipid layer and cellular elements were removed. The aqueous fraction was used for cytokine determinations.

Milk cytokine assays. Colostral milk IL- $1 \beta$, IL- 6 , IL- 8 , IL10, and TNF- $\alpha$ levels were determined with chemiluminescence enzyme immunometric assays on an IMMULITE Immunoassay Analyzer (IMMULITE IL-1 $\beta$, IL-6, IL-8, IL-10, and TNF- $\alpha$ assays, Diagnostic Products Corporation, Los Angeles, CA). All fractions were assayed undiluted. The lower limits of detection are as follows: IL- $1 \beta, 1.5 \mathrm{pg} / \mathrm{mL}$; IL-6, $2 \mathrm{pg} / \mathrm{mL}$; IL-8, $2 \mathrm{pg} / \mathrm{mL} ; \mathrm{IL}-10,2$ $\mathrm{pg} / \mathrm{mL}$; and TNF, $1.7 \mathrm{pg} / \mathrm{mL}$, respectively. IMMULITE cytokine controls were included in each analytical run. Intraassay and interassay precision performances of the assays were determined in 10 replicates in a single run and in 20 different runs, respectively, from the quality control data of the laboratory. To evaluate the influence of breast milk components on measured cytokine concentrations, known amounts of recombinant cytokines were added to a milk sample and then analyzed. In addition to the endogenous cytokine, $91-94 \%$ (means of two determinations) of the exogenous cytokine was detected: IL-1 $\beta, 91 \%$; IL-6, 94\%; IL-8, 93\%; IL-10, 90\%; and TNF- $\alpha$, $92 \%$, respectively. Moreover, coefficients of variations were the following: IL-1 $\beta, 10.1 \%$; IL-6, 7,5\%; IL-8, 8.4\%; IL-10, $10.9 \%$; and TNF- $\alpha, 7.8 \%$, respectively.

Statistical analysis. Unless otherwise specified, results are expressed as mean $( \pm \mathrm{SD})$ and median (upper-lower quartiles). Those samples that had concentrations below the cut-off were assessed to a value corresponding to half the cut-off value. Human milk samples were also grouped into third postpartum day neonatal jaundice and non-neonatal jaundice mothers' groups, with 29 and 32 samples per group, respectively.

Because the concentrations of the cytokines were not normally distributed, paired analyses was performed with Wilcoxon signed rank test and unpaired with the Mann-Whitney $U$ test, and correlations were analyzed with Spearman rank order correlation coefficient test. A probability level of $<0.05$ was considered to be statistically significant.

Ethics. The research protocol was approved by the Hospital Ethical Committee for Human Research of the participating Hospitals.

\section{RESULTS}

Cytokine concentrations in colostrum. We analyzed 61 milk samples, 32 from mothers of neonates with NJ, and 29 control samples from mothers of at term neonates without NJ, collected at a postnatal age (mean $\pm \mathrm{SD}$ ) of $49.3 \pm 12$ and $48.8 \pm 10 \mathrm{~h}$ after delivery, respectively. Measurable immunoreactive levels of IL-6, IL-8, and TNF- $\alpha$ were observed in all colostral milk ( 3 d) samples, whereas IL- $1 \beta$ and IL-10 were less commonly detected (78\% and $60 \%$, respectively). The mothers identified as breast-feeding neonates with NJ were comparable in their and those of the respective neonates anthropometrical, clinical, and peripartal characteristics, except for bilirubin serum levels (Table 1).

The concentration (median, upper-lower quartiles) of IL-1 $\beta$ (8.7, 3.7-15.2 versus $4.0,2.5-9.0 \mathrm{pg} / \mathrm{mL}, p<0.03)$ were significantly higher in the colostrum of mothers breast-feeding neonates with $\mathrm{NJ}$, in comparison with those breast-feeding neonates without $\mathrm{NJ}$, while the concentrations (median, upper-lower quartiles) of bilirubin in infants whose mothers did
Table 1. Participants anthropometrical, clinical, and peripartal characteristics

\begin{tabular}{lcc}
\hline & Controls & Neonatal jaundice \\
\hline Mothers & & \\
Age $(\mathrm{y})$ & $31.2 \pm 1.1$ & $31.1 \pm 0.9$ \\
Education $(\mathrm{y})$ & $10.6 \pm 3$ & $10.5 \pm 2$ \\
Parity $(\mathrm{n})$ & $2.05 \pm 1$ & $2.07 \pm 1$ \\
BMI $\left(\mathrm{kg} / \mathrm{m}^{2}\right)$ & $25.3 \pm 4.0$ & $25.7 \pm 4.2$ \\
Vaginal/cesarean delivery & $23 / 6$ & $26 / 6$ \\
Neonates & 29 & 32 \\
Gestational age (wk) & $40.1 \pm 0.4$ & $40.0 \pm 0.3$ \\
Sex & & \\
Male (\%) & 42 & 44 \\
Apgar score & $9.2 \pm 0.1$ & $8.8 \pm 0.4$ \\
1 min & $9.8 \pm 0.1$ & $9.5 \pm 0.1$ \\
5 min & $3206 \pm 447$ & $3304 \pm 370$ \\
Birth weight (kg) & -7.3 & -5.6 \\
\% Physiologic decrease & $2975 \pm 428$ & $3120 \pm 341$ \\
At discharge (kg) & $4.7(4.4-7.4)$ & $14.2(13.9-15.1)$ \\
Total serum bilirubin (mg/dL) &
\end{tabular}

Mean \pm SD or median (upper-lower quartiles).

not have detectable colostral IL-1 $\beta$ were unaffected, $14.4,14.0-15.1$ versus $14.4,13.6-16.6 \mathrm{mg} / \mathrm{dL}$, respectively. A similar trend was seen for IL-6 $(17.5,11.6-32.3$ versus 15.5 , $6.0-40.8 \mathrm{pg} / \mathrm{mL}, p=0.10)$, IL-8 $(751.5,164-3496.0$ versus 570.5, 245.0-1968.0 pg/mL, $p=0.09)$, IL-10 (4.3, 2.5-46.0 versus $6.5,2.5-9.5 \mathrm{pg} / \mathrm{mL}, p=0.10)$, and for TNF- $\alpha$ (28.6, 19.5-46.0 versus 21.9,18.6-37.2 pg/mL, $p=0.45$ ) (Table 2).

Correlations between the different cytokines in colostrum from mothers of neonates with $N J$. The concentrations in colostrum of IL- $1 \beta$, IL-6, IL-8, IL-10, and TNF- $\alpha$ correlated with each other (Table 3). There were strong correlations between the concentrations for IL- 6 , IL- 8 , IL-10, TNF- $\alpha$, and IL- $1 \beta$. The concentrations of IL-10 also correlated with the concentrations of IL- 8 and TNF- $\alpha$, and a correlation was seen between IL-6 and IL-8 (Table 3).

Correlations between IL-1 $\beta$ concentrations in colostrum and serum bilirubin levels of neonates with $N J$. The concentration (median, upper-lower quartiles) of bilirubin in neonatal

Table 2. Concentrations of $I L-1 \beta, I L-6, I L-8, I L-10$, and $T N F-\alpha$ in colostrum

\begin{tabular}{lccr}
\hline & $\begin{array}{c}\text { Control } \\
(n=29)\end{array}$ & $\begin{array}{c}\text { Neonatal jaundice } \\
(n=32)\end{array}$ & \multicolumn{1}{c}{$p$} \\
\hline IL-1 $\beta(\mathrm{pg} / \mathrm{mL})$ & $4.0(2.5-9.0)$ & $8.7(3.7-15.2)$ & $<0.03$ \\
IL-6 $(\mathrm{pg} / \mathrm{mL})$ & $15.5(6.0-40.8)$ & $17.5(11.6-32.3)$ & 0.10 \\
IL-8 $(\mathrm{pg} / \mathrm{mL})$ & $583.0(247.0-7052.0)$ & $751.5(464.5-3496.0)$ & 0.09 \\
IL-10 $(\mathrm{pg} / \mathrm{mL})$ & $6.5(2.5-9.5)$ & $4.3(2.5-12.9)$ & 0.10 \\
TNF- $\alpha(\mathrm{pg} / \mathrm{mL})$ & $21.9(18.6-37.5)$ & $28.6(19.5-46.0)$ & 0.45 \\
\hline
\end{tabular}

Median (upper-lower quartiles).

Table 3. Correlations ( $r$ ) between the different cytokines in colostrum

\begin{tabular}{lccccc} 
Cytokine & IL-1 $\beta$ & IL-6 & IL-8 & IL-10 & TNF- $\alpha$ \\
\hline IL- $\beta$ & - & & & & \\
IL-6 & $0.46^{*}$ & - & & & \\
IL-8 & $0.58^{* *}$ & $0.43^{*}$ & - & & \\
IL-10 & $0.61^{* *}$ & NS & $0.38^{*}$ & - & \\
TNF- $\alpha$ & $0.65^{* *}$ & NS & NS & $0.62^{* *}$ & - \\
\hline
\end{tabular}

$* p<0.05, * * p<0.001$. 
serum of jaundiced neonates was $14.2(13.9-15.1) \mathrm{mg} / \mathrm{dL}$. Neither IL-1 $\beta$ concentrations in colostrum nor other studied cytokines were correlated to serum bilirubin concentrations of neonates with $\mathrm{NJ}$.

\section{DISCUSSION}

In this study, we present novel evidence suggesting that the mammary glands' immunologic function, significantly influencing colostrum provision of the inflammatory cytokines for breast-feeding, may affect jaundice development in neonates. The identification of elevated IL- $1 \beta$ concentration in colostrum of mothers with jaundiced infants offers support to the hypothesis that some clinical consequences of breast-feeding on infancy might be initiated and/or enhanced by breast milk cytokines altered levels $(22,23)$.

Breast-fed infants have higher bilirubin levels than formulafed infants, often presenting bilirubin levels $>12 \mathrm{mg} / \mathrm{dL}$, with danger of brain damage in severe cases (1). Suggested mechanisms for these uncommon-to-rare findings include dehydration due to poor transfer of human milk to the neonate inhibition of hepatic excretion of bilirubin, and intestinal absorption of bilirubin (enterohepatic circulation) (6). This conclusion is in line with the observation that exposure to various breast milk components/substances such as pregnane-3 $20 \beta$-diol, nonesterified fatty acids, and glucuronidase, or acquired cholestatic injury (e.g. drugs, hormones, proinflammatory cytokines, biliary obstruction or destruction) results in altered expression and function of hepatic uptake and excretory systems, changes that may maintain and contribute to cholestasis and jaundice (9). Concerning intestinal absorption a key step in the enterohepatic circulation of bilirubin, the molecular basis remains unclear. UDPGT is the conjugating enzyme responsible for the formation of the glucuronides. $\beta$-glucuronidase is the enzyme responsible for the deconjugation of these glucuronides $(6-8,15)$.

Human milk is an important source of other bioactive substances including hormones, growth factors, and immunologic factors such as cytokines, but the functional consequences of an overexpression or of a down-regulation of most milk immunomodulatory constituents in neonates are largely unknown. The synthesis, processing, secretion, and activity of cytokines are tightly regulated events. For instance, the presence of an IL-1 receptor antagonist is an important mechanism through which IL-1 signaling is down-regulated, and therefore its activity is reduced (24). Of interest, IL- $1 \beta$ receptor antagonists have been measured in human breast milk (25). To what extent the biologic effect of the cytokine in milk is modulated by the presence of soluble receptors and other cytokine antagonists is open to speculation. As the intensive relationship between the mother and the infant during pregnancy and breast-feeding may result in modulation of the immune system of the infant to favor the development of immune phenotype, it is possible that altered immunologic properties of the colostrum, having an abundance of cytokines, in turn affect the maturation of the absorption mechanisms of the gastrointestinal tract and thus the health status of the breast-fed infant. Although cytokines are known to play a critical role in the intestinal absorption, the molecular basis remains unclear. Several studies have shown that enterocytes can constitutively express pro-inflammatory cytokines (19) and this response is up-regulated by inflammatory stimuli such as endotoxin and IL-1 $\beta$ (26,27). Previously, Monshouwer et al. (14) found that recombinant human proinflammatory cytokines IL- $1 \alpha$, IL-6, and TNF- $\alpha$ played an important role in the depression of CY450, decreasing glucuronidation activities dose dependently. In addition, the cholestatic effect of cytokines is believed to result from the repression of genes that normally mediated the hepatic uptake, metabolism, and biliary excretion of bile salts and various non-bile salt organic anions (e.g. bilirubin) $(12,13)$. Our finding that cytokine exposure is associated with hyperbilirubinemia is not surprising given that a reduced availability of IL- $1 \alpha$ was evidenced in breast-feeding smoking mothers (28).

There are certain limitations in our study. First, only colostral samples were collected in early postpartum. It is well established that milk composition differs with delivery modalities, increasing parturition, throughout the day and at each feeding. Generally, milk proteins that are produced and secreted in the mammary gland are expected to constitute the largest proportion of protein in human milk, and to have more postpartum variation than serum proteins that are passively transferred into milk $(22,29)$. Having multiple cytokine measures taken over time from breast-feeding mothers would permit verification of the assumption underlying this analysis. In addition, we did not determine before test bilirubin levels the totality of the exposures to components in human milk, as important as their concentrations in the exclusively breast-fed infants. Finally, we may lack sufficient power to detect additional correlations of colostral cytokines (i.e. IL-6 and TNF$\alpha$ ), also known to influence glucuronidation in vitro (14), with serum bilirubin levels of the infants.

However, the study has several strengths. Prospective assessment clarifies the temporal relationships between exposure to cytokines and neonatal jaundice. Our measure of cytokines in colostrum has been used in previous studies and is valid. In most studies, in fact, IL- $1 \alpha$ and IL- $1 \beta$ activities are indistinguishable (24), whereas the balance of pro-inflammatory (e.g. IL-6, IL-8, TNF- $\alpha$, granulocyte-macrophage colonystimulating factor, etc.) and anti-inflammatory signals (e.g. IL-10, IL-15, etc.) generated by intestinal epithelium is critical in mounting an effective acute response (19). In addition, nearly $30 \%$ of mothers had no detectable IL-10 at any time during the first month postpartum (30), whereas IL- $1 \beta$ in milk was more frequently detected (31). Thus, the fact that $60-$ $100 \%$ all the milk samples in the study contained cytokines provides a large enough group to be confident of the results and of the measurable presence of cytokines in the early milk of mothers with jaundiced newborns. Nevertheless, it is premature to known how the findings will pertain to the classic early and later breast milk NJ.

In conclusion, we demonstrated a higher concentration of cytokines in colostral milk in mothers of neonates with hyperbilirubinemia compared with those without. Elevated colostral cytokines concentrations provide additional data to the delineation of the pathophysiological mechanism that includes 
mammary gland immunologic function in the cascade of events that can lead to NJ. Prospective studies are required to concurrently determine whether the activity of $\beta$-glucuronidase in human milk are in correlation with the concentrations of any of the colostral cytokines and to thoroughly assess the differences in the composition of breast milk from mothers with different breast milk jaundice histories and the immunologic and clinical consequences of such for the offspring.

Acknowledgments. The authors thank Giuliana Bertocco for excellent technical assistance.

\section{REFERENCES}

1. Newman AJ, Gross S 1963 Hyperbilirubinemia in breast-fed infants. Pediatrics 32:995-1001

2. Maisels MJ, Newman TB 1995 Kernicterus in otherwise healthy, breast-fed term newborns. Pediatrics 96:730-733

3. Lascari AD 1986 'Early' breast-feeding jaundice. Clinical significance. J Pediatr 108:156-158

4. Amato M, Howald H, von Muralt G 1985 Fat content of human milk and breast milk jaundice. Acta Paediatr Scand 74:805-806

5. Bertini G, Dani C, Tronchin M, Rubaltelli FF 2001 Is breast-feeding really favoring early neonatal jaundice? Pediatrics 107:e41-

6. Gourley GR, Arend RA 1986 Beta-glucuronidase and hyperbilirubinemia in breastfed and formula-fed babies. Lancet 1:644-646

7. Gourley GR, Gourley MF, Arend RA, Palta M 1989 The effect of saccharolactone on rat intestinal absorption of bilirubin in the presence of human breast-milk. Pediatr Res 25:234-238

8. Alonso EM, Whitington PM, Whitington SH, Rivard WA, Given G 1991 Enterohepatic circulation of monoconjugated bilirubin in rats fed with human milk. J Pediatr 118:425-430

9. Trauner M, Wagner M, Fickert P, Zollner G 2005 Molecular regulation of hepatobiliary transport systems: clinical implications for understanding and treating cholestasis. J Clin Gastroenterol 39:S111-S124

10. Honsawek S, Chongsrisawatn V, Vejchapipat P, Thawornsuk N, Tangkijvanich P, Poovorawan Y 2005 Serum interleukin-8 in children with biliary atresia, relationship with disease stage and biochemical parameters. Pediatr Surg Int 21:73-77

11. Kimura F, Miyazaki M, Suwa T, Sugiura T, Shinoda T, Itoh H, Nagakawa K, Ambiru S, Shimizu H, Yoshitome H 2001 Anti-inflammatory response in patients with obstructive jaundice caused by biliary malignancy. J Gastroenterol Hepatol 16:467-472

12. Bolder U, Ton-Nu HT, Schteingart CD, Frick E, Hofmann AF 1997 Hepatocyte transport of bile acids and organic anions in endotoxemic rats. Impaired uptake and secretion. Gastroenterology 112:214-225
13. Moseley RH 1997 Sepsis-associated cholestasis. Gastroenterology 112:302-306

14. Monshouwer M, Witkamp RF, Nujmeir SM, Van Amsterdam JG, Van Miert AS 1996 Suppression of cytochrome P450- and UDP glucuronosyl transferasedependent enzyme activities by proinflammatory cytokines and possible role of nitric oxide in primary cultures of pig hepatocytes. Toxicol Appl Pharmacol 137:237-244

15. Brodersen R, Hermann LS 1963 Intestinal reabsorption of unconjugated bilirubin-A possible contributing factor in neonatal jaundice. Lancet $1: 1242$

16. Gourley GR 1998 Pathophysiology of breast-milk jaundice. In: Polin RA, Fox WW (eds) Fetal and Neonatal Physiology, W.B. Saunders Co mpany, Philadelphia pp 1499-1505

17. Kivlahan C, James EI 1984 The natural history of neonatal jaundice. Pediatrics 74:364-370

18. Arias IM, Gartner LM, Seifter S, Furman M 1964 Prolonged neonatal unconjugated hyperbilirubinemia associated with breast feeding and a steroid, pregnane3(alpha),20(beta)-diol in maternal milk that inhibits glucuronides formation in vitro. J Clin Invest 43:2037-2047

19. Nanthakumar NN, Fusunyan RD, Sanderson I, Walker WA 2000 Inflammation in the developing human intestine: a possible pathophysiologic contribution to necrotizing enterocolitis. Proc Natl Acad Sci U S A 97:6043-6048

20. Gourley GR 2002 Breast-feeding, neonatal jaundice and kernicterus. Semin Neonatol 7:135-141

21. American Academy of Pediatrics Subcommittee on Hyperbilirubinemia 2004 Management of hyperbilirubinemia in the newborn infant 35 or more weeks of gestation. Pediatrics 114:297-316

22. Goldman AS, Chheda S, Garofalo R, Schmalstieg FC 1996 Cytokines in human milk: properties and potential effects upon the mammary gland and the neonate. J Mammary Gland Biol Neoplasia 1:251-258

23. Orlando S 1995 The immunologic significance of breast milk. J Obstet Gynecol Neonatal Nurs 24:678-683

24. Dinarello CA 1997 Interleukin 1. Cytokine Growth Factor Rev 8:253-265

25. Buescher ES, Malinowska I 1996 Soluble receptors and cytokine antagonists in human milk. Pediatr Res 40:839-844

26. Yang SK, Eckmann L, Panja A, Kagnoff MF 1997 Differential and regulated expression of $\mathrm{C}-\mathrm{X}-\mathrm{C}, \mathrm{C}-\mathrm{C}$, and $\mathrm{C}$-chemokines by human colon epithelial cells. Gastroenterology 113:1214-1223

27. De Franco AL, Crowley MT, Finn A, Hambleton J, Weinstein SL 1998 The role of tyrosine kinases and map kinases in LPS-induced signaling. Prog Clin Biol Res 397:119-136

28. Zanardo V, Nicolussi S, Cavallin S, Trevisanuto D, Barbato A, Faggian D, Favaro F, Plebani M 2005 Effect of maternal smoking on breast milk interleukin1- $\alpha, \beta$-endorphin, and leptin concentrations. Environ Health Perspect 113:1410-1413

29. Londerdal B, Atkinson S 1995 Human milk proteins. In: Jensen R (ed) Handbook of Milk Composition. Academic Press, San Diego pp 351-368

30. Fituch CC, Palkowetz KH, Goldman AS, Schanler RJ 2004 Concentrations of IL-10 in preterm human milk and in milk from mothers of infants with necrotizing enterocolitis. Acta Paediatr 93:1496-1500

31. Munoz C, Enders S, van der Meer J, Schlesinger L, Arevalo M, Dinarello C 1990 Interleukin-1 beta in human colostrum. Res Immunol 141:505-513 